\title{
KINERJA EKSPERIMEN KOLEKTOR SURYA DENGAN MEDIA TRANSFER PANAS BATU GRANIT DAN MINYAK KELAPA SAWIT
}

\author{
Mustaqim(1), Ahmad Farid ${ }^{2)}$, Hadi Wibowo ${ }^{3)}$, Muhamad Yusuf ${ }^{4)}$, Najarudin ${ }^{5)}$, Winarno6), \\ Arfian ${ }^{7)}$ \\ 1,2,3,5,6,7)Teknik Mesin Universitas Pancasakti Tegal, Jl. Halmahera km.1 Tegal \\ ${ }^{4)}$ Teknik Sipil Universitas Pancasakti Tegal, Jl. Halmahera km.1 Tegal \\ banktaqim@gmail.com
}

\begin{abstract}
Abstrak - Telah dilakukan penelitian kinerja kolektor panas matahari dengan media penyerap panas batu granit sebagai upaya memanfaatkan sumber daya alam Indonesia. Ukuran kolektor panas matahari adalah 100 $\mathrm{cm} \times 60 \mathrm{~cm} \times 5 \mathrm{~cm}$. Digunakan media penyerap panas matahari adalah udara, batu granit ukuran butiran $1 \mathrm{~mm}$, dan batu granit ukuran butiran 3 mm. Fluida kerja penyerap panas kolektor adalah minyak kelapa sawit dengan laju aliran 1,5 LPM. Kemiringan kolektor terhadap cahaya datang matahari $30^{\circ}$ menghadap utara. Pertumbuhan temperature fluida kerja diukur setiap 30 menit selama 6 jam yaitu dari pukul 09.00 WIB sampai 15.00 WIB. Analisis energy dilakukan untuk mengetahui perbandingan kinerja media penyerap panas yang digunakan tersebut. Hasil penelitian menunjukan bahwa beda temperatur fluida kerja masuk dan keluar kolektor tertinggi dicapai antara jam 09.30 sd. Jam 12.00. Kinerja effisiensi kolektor dengan media batu granit butiran $3 \mathrm{~mm}$ lebih baik dibanding dengan menggunakan media udara dan media batu granit butiran $1 \mathrm{~mm}$.
\end{abstract}

Kata kunci: Kolektor Surya, Batu Granit, Minyak Sawit

\section{PENDAHULUAN}

Letak geografis Indonesia yang dilewati garis katulistiwa, sehingga bumi Indonesia mendapatkan energi matahari sepanjang tahun. Hal ini sangat mendukung pemanfaatan energi matahari di Indonesia sebagai sumber energi yang tidak akan habis. Memanfaatkan energi surya tersebut antara lain dapat menggunakan perangkat pengumpul energi matahari yang sering disebut kolektor surya [1]-[3]. Kolektor surya dapat digunakan sebagai alat pemanas air tenaga matahari yang peruntukannya biasa digunakan dalam skala rumahan ataupun indutri dan perhotelan [4], [5]. Kolektor surya adalah teknologi untuk memanfaatkan energi matahari. Kolektor surya terdiri dari tiga bagian, yaitu pelat absorber berwarna gelap, pipa panas dan penutup transparan dari kaca atau plastik.
Sinar matahari menembus penutup transparan dan memengaruhi pelat berwarna gelap, sehingga suhu pelat naik dan panas ini diserap oleh fluida di dalam pipa panas. Tipe ini umumnya bekerja pada suhu di bawah $90{ }^{\circ} \mathrm{C}$ [6]. Tentunya energi matahari lebih murah dan lebih ramah lingkungan jenis energy lainnya. Untuk menciptakan solar water heater yang optimal harus diperhatikan faktor yang mempengaruhi kinerja solar water heater yaitu kodisi cuaca, jenis fluida yang digunakan pada pipa kolektor dan material media transfer panas kolektor surya. Pada penelitian ini akan dikaji pengaruh penggunaan media transfer panas batu granit dan fluida kerja minyak sawit pada kolektor surya water heater jenis plat datar terhadap kinerja penyerapan panas matahari. 


\section{LANDASAN TEORI}

Sebagai suatu gambaran mengenai tiga cara perpindahan panas dalam sebuah alat pemanas air surya, panas mengalir secara konduktif sepanjang plat penyerap dan melalui dinding saluran. Kemudian panas dipindahkan ke fluida dalam saluran dengan cara konveksi, apabila sirkulasi dilkukan dengan sebuah pompa, maka kita menyebutnya dengan konveksi paksa. Pelat penyerap yang panas itu melepaskan panas ke pelat penutup kaca (umumnya menutupi kolektor) dengan cara konveksi alamiah dan dengan cara radiasi. Selanjutnya panas akan dialirkan secara konduksi didalam media padat yang digunakan [6]. Panas mengalir secara konduksi dari daerah yang bertemperatur tinggi ke daerah yang bertemperatur rendah. Laju perpindahan panas dinyatakan dengan hukum Fourier,

$$
Q=-k \cdot A \frac{d T}{d x}
$$

dimana $\mathrm{Q}$ adalah laju perpindahan panas dalam watt, $\mathrm{k}$ adalah konduktifitas termal bahan dalam W/m.C, A adalah luas penampang normal arah perpindahan dalam $\mathrm{m}^{2}, \quad \frac{d T}{d x}$ adalah gradien temperatur dalam arah aliran panas dalam ${ }^{\circ} \mathrm{C} / \mathrm{m}$. Perpindahan panas konveksi dapat dinyatakan dengan hukum Newton, sebagai berikut,

$$
q=h A(T w-T)
$$

dimana $\mathrm{h}$ adalah koefisien konveksi dalam $\mathrm{W} / \mathrm{m}^{2} \mathrm{C}, \quad$ A adalah Luas penampang perpindahan panas dalam $\mathrm{m}^{2}, \mathrm{~T}_{\mathrm{w}}$ adalah temperatur dinding dalam ${ }^{\circ} \mathrm{C}, \mathrm{T}$ adalah adalah temperatur fluida dalam ${ }^{\circ} \mathrm{C}, \mathrm{q}$ adalah laju perpindahan panas dalam watt. Penukaran panas netto secara radiasi termal antara benda hitam adalah,

$$
q=-\sigma A\left(T_{1}^{4}-T_{2}^{4}\right)
$$

dimana $\sigma$ adalah tetapan Stefan Boltzman besarnya $5,67 \times 10-8 \mathrm{w} / \mathrm{m}^{2} . \mathrm{k} 4, \mathrm{~T}$ adalah temperatur mutlak benda dalam $\mathrm{K}$, A adalah luas bidang radiasi dalam $\mathrm{m}^{2}$.

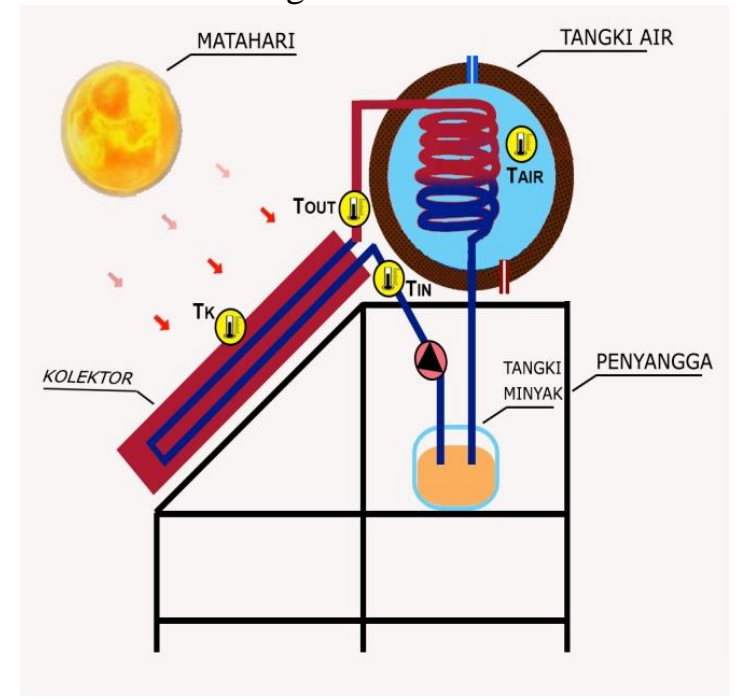

Gambar 1. Set-up Perangkat Uji

Cara kerja dari alat ini adalah minyak sawit dialirkan ke dalam kolektor surya untyk menerima panas dan selanjutnya dialirkan ke tangka penampung air untuk memberikan panas ke air. Minyak kelapa sawit adalah minyak nabati edibel yang didapat dari mesocarp buah pohon kelapa sawit, umumnya dari spesies Elaeis guineensis, dan sedikit dari spesies Elaeis oleifera dan Attalea maripa. Densitas CPO pada suhu $25^{\circ} \mathrm{C}$ (Tabel 1) berkisar antara $0,909-0,917 \mathrm{~g} / \mathrm{mL}$, sedangkan pada suhu $55^{\circ} \mathrm{C}$ (Tabel 2), nilai densitasnya menurun menjadi berkisar antara $0,888-0,892 \mathrm{~g} / \mathrm{mL}$.

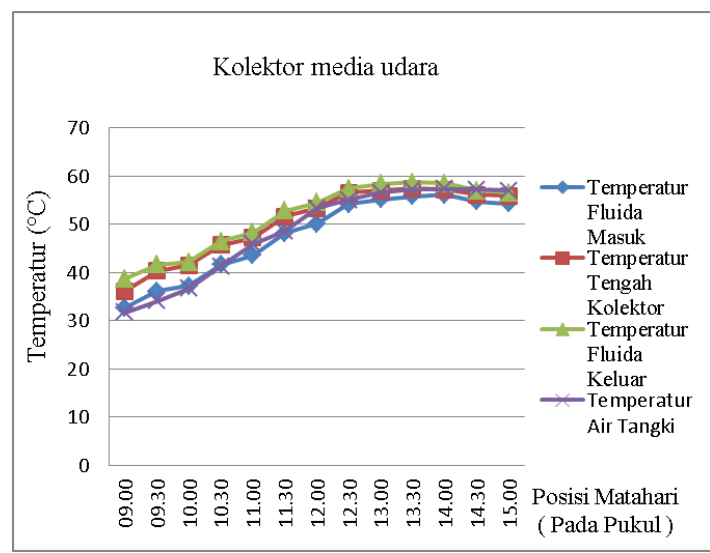

Gambar 2. Pertumbuhan temperature minyak sawit pada kolektor media udara 


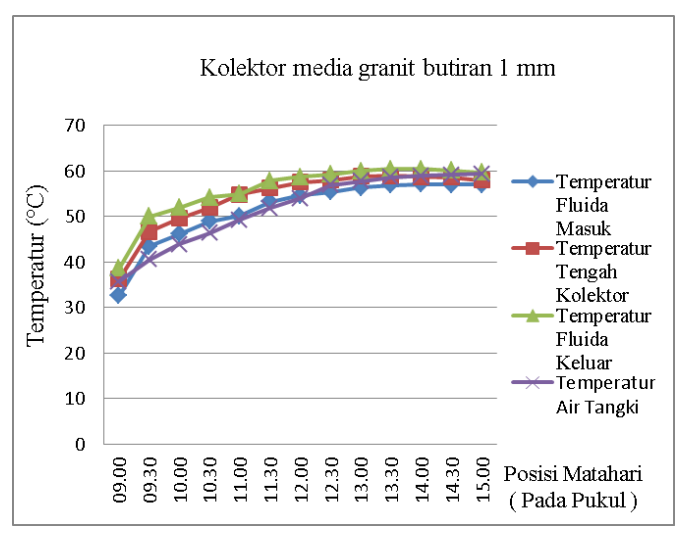

Gambar 3. Pertumbuhan temperature minyak sawit pada kolektor media granit ukuran $1 \mathrm{~mm}$

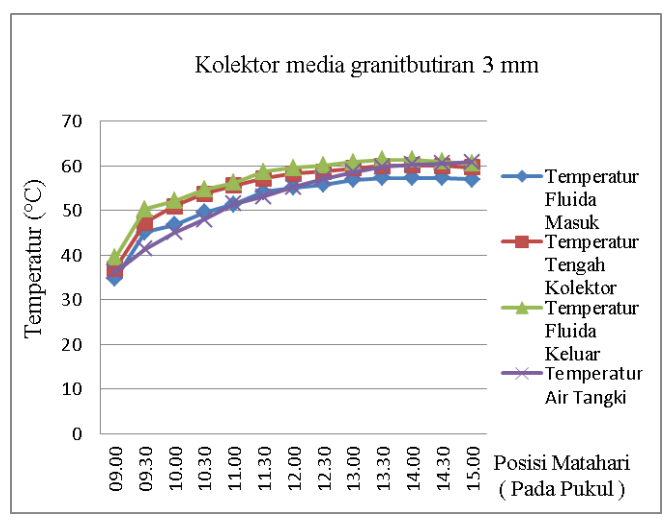

Gambar 4. Pertumbuhan temperature minyak sawit pada kolektor media granit ukuran $3 \mathrm{~mm}$

Besar energi surya masuk ke dalam kolektor adalah besarnya intensitas radiasi matahari dikalikan dengan luasan kolektor yang terkena radiasi matahari tersebut,

$$
\operatorname{Qin}=I_{T} \cdot A_{C}
$$

dimana $\mathrm{Q}_{\text {in }}$ adalah panas surya yang masuk kolektor dalam watt, $\mathrm{I}_{\mathrm{T}}$ adalah Intensitas radiasi matahari dalam $\mathrm{W} / \mathrm{m}^{2}, \mathrm{~A}_{\mathrm{c}}$ adalah luas permukaan kolektor dalam $\mathrm{m}^{2}$. Kalor yang diterima oleh kolektor dapat dirumuskan sebagai berikut,

Kalor Yang Diserap minyak sawit dari kolektor adalah

$$
\text { Quse }=\dot{\operatorname{m}} \cdot C_{p} \cdot\left(T_{o}-T_{i}\right)
$$

Copyright $(2019$ FT-UHAMKA. - All rights reserved DOI: $10.22236 /$ teknoka.v\%vi\%i.4289 dimana Quse adalah kalor yang diserap fluida dalam watt, $\dot{m}$ adalah laju aliran massa fluida dalam $\mathrm{kg} / \mathrm{s}, \mathrm{C}_{\mathrm{p}}$ adalah panas jenis fluida dalam $\mathrm{J} / \mathrm{kg} .{ }^{\circ} \mathrm{C}, \mathrm{T}_{\mathrm{o}}$ dan $\mathrm{T}_{\mathrm{i}}$ adalah temperatur fluida keluar dan masuk kolektor dalam ${ }^{\circ} \mathrm{C}$. Efisiensi kolektor adalah perbandingan panas yang diserap oleh fluida dengan intensitas matahari yang masuk kolektor yang merupakan kualitas performansi sebuah kolektor dalam kinerjanya dihitung dengan persamaan,

$$
\eta=\frac{Q_{\text {use }}}{Q_{\text {in }}}
$$

dimana $\mathrm{Q}_{\text {use }}$ adalah kalor yang diserap fluida dalam watt, $Q_{\text {in }}$ adalah panas surya yang masuk kolektor dalam watt.

\section{METODOLOGI PENELITIAN}

Sebagaimana dapat dilihat pada Gambar 1. Ukuran kolektor panas matahari adalah $100 \mathrm{~cm}$ x $60 \mathrm{~cm}$ x $5 \mathrm{~cm}$. Pipa fluida penukar kalor berbahan tembaga dengan diameter $10 \mathrm{~mm}$. Tiga media transfer panas dari surya ke pipa minyak digunakan udara, butir granit $1 \mathrm{~mm}$ dan butir granit 3 $\mathrm{mm}$. Fluida kerja penyerap panas kolektor adalah minyak kelapa sawit dengan laju aliran 1,5 LPM. Kemiringan kolektor terhadap cahaya datang matahari $30^{\circ}$ menghadap utara. Pertumbuhan temperature fluida kerja diukur setiap 30 menit selama 6 jam yaitu dari pukul 09.00 WIB sampai 15.00 WIB.

Cara penelitian adalah minyak sawit dialirkan ke dalam kolektor surya dengan laju aliran 1,5 LPM untuk menerima panas kolektor dan selanjutnya dialirkan ke tangki penampung air untuk memberikan panas yang di bawanya ke air di dalam tangka penampung. Untuk mengkaji kinerja penyerapan kalor oleh kolektor surya ditempatkan thermometer sebagai alat ukur temperature minyak sawit pada sisi masuk dan keluar kolektor surya.

Data temperature dicatat, hal ini dilakukan dengan cara yang sama untuk semua kolektor baik dengan media udara, butir granit $1 \mathrm{~mm}$ maupun butir granit 3 $\mathrm{mm}$. selanjutnya data diolah untuk mendapatkan karakter pengaruh media

Seminar Nasional TEKNOKA ke - 4, Vol. 4, 2019 ISSN No. 2502-8782 
tersebut terhadap kinerja penyerapan panas kolektor. Data diambil pada keadan hari matahari cerah tak berawan.

\section{HASIL DAN PEMBAHASAN}

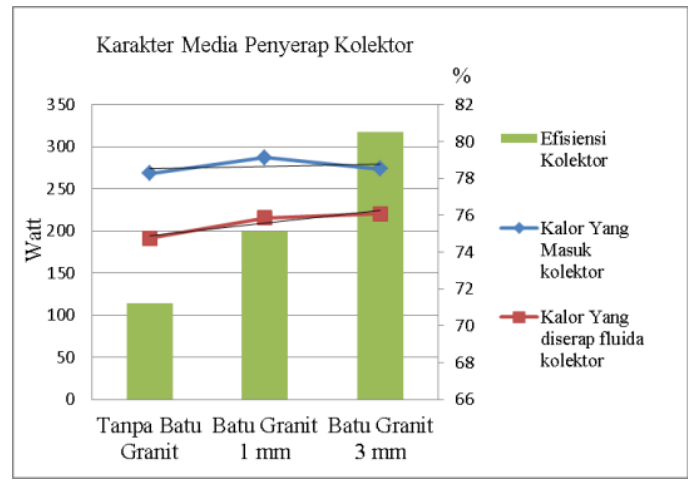

Gambar 5. Perbandingan kinerja penyerapan kalor oleh media udara(tanpa granit), media granit $1 \mathrm{~mm}$ dan media granit $3 \mathrm{~mm}$

Dari Gambar 2, 3 dan 4 dapat dilihat bahwa kecenderungan penyerapan panas mencapai puncaknya pada tengah hari hal ini sejalan dengan penelitian-penelitian terdahulu [6], [7]. Gambar 2 menunjukan pertumbuhan minyak sawit pada kolektor media udara. Gambar tersebut memperlihatkan bahwa kenaikan temperatur minyak mencapai temperatur tertinggi pada tengah hari sebesar $56,2^{\circ} \mathrm{C}$ temperatur fluida keluar sebesar $58,8^{\circ} \mathrm{C}$ temperatur tengah kolektor sebesar $57,5^{\circ} \mathrm{C}$ dan temperatur air tangki sebesar $57,4^{\circ} \mathrm{C}$.

Gambar 3 menunjukan penggunaan media penyerap panas batu granit dengan ukuran butiran $1 \mathrm{~mm}$ menyebabkan kenaikan beberapa temperatur secara signifikan, temperatur tertinggi fluida masuk dicapai sebesar $56,9^{\circ} \mathrm{C}$ temperatur fluida keluar sebesar $60,5^{\circ} \mathrm{C}$ temperatur tengah kolektor sebesar $59^{\circ} \mathrm{C}$ dan temperatur air tangki sebesar $59,4^{\circ} \mathrm{C}$. Gambar 4 menunjukan bahwa penggunaan media penyerap panas batu granit dengan ukuran butiran $3 \mathrm{~mm}$ memberikan kenaikan tertinggi fluida masuk sebesar $57,4^{\circ} \mathrm{C}$ temperatur fluida keluar sebesar $61,4^{\circ} \mathrm{C}$ temperatur tengah kolektor sebesar $60,1^{\circ} \mathrm{C}$ dan temperatur air tangki sebesar $60,9^{\circ} \mathrm{C}$
Gambar 5 menunjukan perbandingan kinerja penyerapan kalor oleh media udara (tanpa granit), media granit $1 \mathrm{~mm}$ dan media granit $3 \mathrm{~mm}$ pada kolektor surya. Dapat dilihat pada gambar bahwa bahwa efisiensi kolektor tertinggi dicapai oleh penggunaan media penyerap batu granit ukuran butiran $3 \mathrm{~mm}$ sebesar $80,5 \%$, kalor masuk kolektor sebesar 273,93 watt, minyak sawit mampu menyerap kalor sebesar 220,7 watt. Kemudian diikuti oleh media penyerap batu granit ukuran butiran $1 \mathrm{~mm}$ effisiensi sebesar $75,1 \%$, kalor masuk kolektor sebesar 287,052 watt, minyak sawit mampu menyerap kalor sebesar 215,8 watt.

Sedangkan effisiensi kolektor dengan media udara ( tanpa granit) mampu mencapai $71,2 \%$, kalor masuk kolektor sebesar 268,482 watt minyak sawit mampu menyerap kalor sebesar 191,3 watt.

\section{SIMPULAN}

Dari pengujian kolektor surya tipe plat datar dengan media penyerap panas batu granit pada kolektor surya water heater dengan fluida minyak sawit dapat disimpulkan bahwa penggunaan batu granit meningkatkan penyerapan panas surya dan dapat mempertahankan temperatur tetap tinggi untuk waktu yang relatif lama dibanding media udara. Ukuran butiran media batu granit $3 \mathrm{~mm}$ memberikan nilai penyerapan kalor yang paling tinggi dibanding dengan media udara dan media batu granit ukuran $1 \mathrm{~mm}$.

\section{KEPUSTAKAAN}

[1] S. Sidopekso, "Studi pemanfaatan energi matahari sebagai pemanas air," vol. 14, no. 1, pp. 23-26, 2011.

[2] I. Amin, N. Harun, and A. Suyuti, "INDONESIA BERBASIS ANALISIS RETScreen INTERNATIONAL THE STUDY OF RENEWABLE ENERGY POTENTIAL IN EASTERN," vol. 709. 
[3] S. Wilayah, A. Dan, D. Septiadi, P. Nanlohy, M. Souissa, and F. Y. Rumlawang, "PROYEKSI POTENSI ENERGI SURYA SEBAGAI ENERGI TERBARUKAN," pp. 22-28.

[4] J. T. Mesin and A. N. Prasetyanta, "PEMANAS AIR ENERGI SURYA DENGAN KOLEKTOR PIPA SERI Tugas Akhir," 2008.

[5] "PEMBUATAN DAN PENGUJIAN KOLEKTOR SURYA PELAT DATAR ( FLAT- PLATE COLLECTORS ) KONDISI STEADY BERDASARKAN STANDAR EN 12975," vol. 12975, 2016.

[6] J. T. Mesin, F. Teknik, and U. N. Jakarta, "KOLEKTOR SURYA SEBAGAI PENYERAP ENERGI TERMAL SURYA Fakultas Teknik Mesin dan Dirgantara , Institut Teknologi Bandung," pp. 13-15, 2010

[7] H. Al-kindi, "ANALISIS TERMAL KOLEKTOR SURYA TIPE PLAT DATAR DENGAN FLUIDA KERJA ETANOL $96 \%$ PADA SISTEM SOLAR WATER HEATER," vol. 06, no. 4, pp. 244251, 2017. 